\title{
La estructuración del comercio y la navegación desde el río de la Plata a Cuba
}

\author{
Hernán Asdrúbal Silva \\ Universidad Nacional del Sur \\ y CONICET, República Argentina
}

El presente trabajo tiene por objeto estudiar la estructuración del tráfico y las exportaciones desde el Río de la Plata a La Habana, teniendo en cuenta básicamente la conjunción de tres factores: a) el desenvolvimiento de la industria saladeril rioplatense, que hizo de las carnes el elemento esencial de exportación hacia La Habana, b) la expansión del sistema esclavista y la transformación productiva cubana, que generó un interesante mercado, c) la rápida conformación de una estructura de comercialización y transporte. Aspectos tales como los vinculados a la producción regional y el establecimiento de los nexos comerciales, el movimiento marítimo y las variantes en la navegación. la significativa presencia de catalanes y norteamericanos en el tráfico, los volúmenes de las principales exportaciones, etc., adquieren significación dentro del proceso histórico que les toca vivir a las posesiones hispanas desde fines del siglo XVIII hasta la Revolución independentista.

La importante vinculación económica que se establece entre el Río de la Plata y Cuba a partir de las últimas décadas del siglo XVIII, obedece a la conjunción de tres factores determinantes: a) el desenvolvimiento de la industria saladeril rioplatense, que hizo de las carnes el elemento esencial de exportación hacia La Habana, b) la expansión del sistema esclavista y la transformación productiva cubana, que generó un interesante mercado, y c) la rápida conformación de una estructura de comercialización y transporte, que permitió un fluído intercambio entre dos regiones $\tan$ alejadas.

\section{Las carnes saladas}

Hasta las últimas décadas del siglo XVIII no se encaró el aprovechamiento de las carnes vacunas en forma industrial. Si bien a lo largo del siglo se había ido produciendo un importante desenvolvimiento de la explotación ganadera, el mismo se dirigió fundamentalmente a la comercialización del cuero y en menor medida de la grasa y el sebo. Los mismos navíos hispanos debían recurrir a productos cárneos elaborados en 
el extranjero, mientras grandes cantidades de carnes rioplatenses quedaban a expensas de los perros cimarrones y las aves de rapiña.

La tardía aparición orgánica de la industria no derivaba de la falta de conocimientos de la potencialidad regional, sino de la necesidad de conjugar adecuadas políticas en materia de producción y comercialización para estas lejanas y marginales regiones del Imperio.

La instalación del Correo Marítimo, que inició en 1767 el tráfico entre La Coruña y el Río de la Plata, dejando su sello indeleble en el proceso aperturista regional, demostró el interés por el fomento de esta industria. La empresa de correos tuvo una voluntad promotora importantísima y, junto a sus objetivos primordiales, fue pionera en el desenvolvimiento de la actividad saladeril. Concolorcorvo, en su famosa descripción publicada en Gijón en 1773, hace referencia a los primeros intentos por servirse adecuadamente de las carnes. "La Dirección General de Correos - dice - había pensado aprovechar mucha parte de esta carne para proveer a las Reales Armadas, en lugar de la mucha que se lleva a España del Norte. Calculados los costos, se halló que con una ganancia bien considerable se podía dar el quintal de carne neta al precio que la venden los extranjeros, en bruto, y que muchas veces introducen carnes de ganados que mueren en las epidemias y de otros animales. Se han conducido a España varios barriles de carne salada de Montevideo y ha parecido muy buena; pero como este proyecto era tan vasto, se abandonó por la Dirección General, siendo digno de lástima que no se emprenda por alguna compañía del país o de otra parte."' El relato es muy importante para el estudio de los orígenes de esta actividad, pero lo es más para nosotros por la referencia concreta a su abandono por parte de una organización estatal desbordada por la magnitud del intento. Sin duda, la vastedad del plan había superado los objetivos esenciales de la empresa, pero había demostrado su utilidad y el posible rédito; de ahí que la experiencia diera pronto proficuos resultados. En pocos años el Río de la Plata llegará a contar con una importante industria dedicada a la elaboración de las carnes.

La aventura de la Dirección General de Correos fue seguida por la actividad de algunos particulares interesados en la industria como Manuel Melián, Francisco Albín y Miguel Rian, registrándose ya para 1780

1 Concolorcorvo: El lazarillo de ciegos y caminantes desde Buenos Aires hasta Lima. Buenos Aires, 1946, pág. 36. 
interesantes embarques desde Montevideo. La producción saladeril tenía importantes requerimientos y de allí que Francisco Medina, hombre de negocios de Buenos Aires, que incursionara incluso en la caza de la ballena y el transporte de sal patagónica, fuera considerado el "gran propulsor" de la industria. Su establecimiento de la estancia del Colla, contaba en la década del 80 con galpones para el saladero y para la tonelería, así como con todo tipo de herramientas, carros y embarcaciones propias. Luego de Medina aparecen entre los productores Tomás Antonio Romero, gran comerciante local, y el escritor Manuel José de Lavardén.

Durante la dominación española, razones económicas vinculadas a los costos de producción y traslado hicieron que la base de la industria estuviera en la Banda Oriental del Río de la Plata.

Dentro de lo que genéricamente llamamos producción saladeril tenemos que diferenciar dos tipos de elaboración y acondicionamiento: la carne salada propiamente dicha (en salmuera) y el charqui o tasajo (seco).

Las posibilidades rioplatenses eran muchas, pero habitualmente se tropezó con la falta de elementos y expertos. Durante el gobierno de Vértiz se habían traído de la Península seis maestros toneleros, que debían aportar sus herramientas y formar discípulos que continuarían su artesanía en el Río de la Plata. En 1785 venían con el mismo fin maestros ingleses. Sin embargo, ni unos ni otros fueron suficientes para el nivel de producción que se quería alcanzar.

Se hicieron embarques hacia España, pero pronto el mejor mercado resultó la isla de Cuba. Luego se sumó el Brasil, pese a la competencia de los saladeros de Río Grande do Sul, así como otros puertos de colonias extranjeras y los Estados Unidos.

La gran ventaja para el desarrollo de esta industria estaba dada por los bajos costos de la materia prima, que permitía competir con éxito en el mercado internacional.

\section{La transformación cubana}

En pocos años, las relaciones económicas con La Habana fueron incrementándose, debido a que el desenvolvimiento de la industria saladeril rioplatense fue concomitante con el incremento de la mano de obra negra y el desarrollo de la economía de plantación. 
En un interesante trabajo dedicado al estudio de la Emigración, población y esclavitud en Cuba, Pablo Tornero muestra cómo la economía local queda enmarcada en las relaciones de producción esclavista, proyectándose más allá del gran desarrollo de la industria azucarera que dinamiza la introducción de mano de obra de aquel origen. Según datos del Consulado de La Habana, de los 65.745 esclavos entrados en Cuba desde 1789 a 1802, únicamente 25.000 estaban en el cultivo de la caña. ${ }^{2}$ En definitiva, la presencia de un dinámico centro de concentración de mano de obra esclava constituyó un fuerte incentivo para el desenvolvimiento de la industria saladeril del Río de la Plata, que encontró en Cuba su mejor mercado.

Además, el impulso de la economía de plantación y de los ingenios hizo de la isla caribeña un gran centro de transacciones, despertando el particular interés de los recientemente independizados norteamericanos que, en determinados momentos, llegaron a monopolizar el tráfico entre el Río de la Plata y La Habana.

\section{La presencia de los catalanes y el tráfico con La Habana}

Fue fundamental para la apertura de un tráfico intensivo y permanente con La Habana el arribo de navieros y comerciantes catalanes al Río de la Plata. Así como generaron una política mercantil agresiva en la puja por ocupar lugares dentro del manejo del movimiento comercial con la Península, ${ }^{3}$ también tuvieron una actitud promotora y competitiva en el intercambio con Cuba.

A partir de la apertura del Río de la Plata al Libre Comercio, Montevideo, principal puerto regional, recibió la reiterada visita de navíos de origen catalán. Con respecto a esta plaza decía el teniente José de Espinosa, integrante de la expedición de Malaspina: "En los arrabales no se ve sino mataderos y carnicerías; toros que huyen de los jinetes que los

2 Tornero, Pablo: "Emigracion, población y esclavitud en Cuba (1765-1817)", Anuario de Estudios Americanos, vol. XLIV, Sevilla, 1987, págs. 239-240; ya planteado sintéticamente en Tornero, Pablo: "Ingenios, plantación y esclavitud: una aproximación al estudio de los esclavos en los ingenios cubanos (1760-1821)", Anuario de Estudios Americanos, vol. XLIII, Sevilla, 1986, pág. 36.

3 Silva, Hernán A.: "El tráfico entre el Mediterraneo español y el Río de la Plata (17781796)", Serie Nuevo Mundo: Cinco Siglos, N." 5, Economía y comercio en América Hispana, Santiago, 1990. 
desjarretan, toros que mueren, y hombres ensangrentados que con la mayor agilidad los desuellan, y extienden y clavan las pieles con estaquillas en el suelo, preparándolas así para que las embarquen los catalanes, que hacen el principal comercio...La población de Montevideo crece de día en día con la franquicia del comercio y la concurrencia de buques de los puertos habilitados de la Península, especialmente las embarcaciones catalanas." 4

Todo lo supieron aprovechar aquellos austeros marinos y comerciantes. "Ellos han hecho - se señalaba en 1787- que se recojan las crines y colas de los caballos; los cuernos del ganado que se mata, que compran por millones y llenándolos de arena saben identificar la carga con el lastre; ellos han movido a limpiar las calles de garras y pedazos de cueros; y a que se aprovechen los sacos que por viejos iban a ser inútiles; y en fin ellos aventurando su persona y su dinero y sus barcos (porque regularmente son navieros, marineros y comerciantes de una pieza) han hecho las primeras tentativas a La Habana con armas, con sebo, carnes y aun con manzanas." 5

El 23 de mayo de 1785 se iniciaba la exportación hacia Cuba, al hacerse a la vela desde Montevideo el paquebote "Los Tres Reyes" a cargo de Juan Ros, natural de la villa de Canet, que despachó a La Habana 202 barriles de carne salada y 100 quintales de charqui. ${ }^{6}$

Sin duda debió irle muy bien en su primer envío y su experiencia influyó en el ánimo de otros comerciantes, armadores y navieros, ya que en un expediente relacionado con José Milá de la Roca -otro promotor del saladero-, el síndico procurador indicaba: "Diez años hace, que la carrera de La Habana se abrió por el capitán catalán don Juan Ros, que condujo su barca de este Río a aquel puerto, con cargamento de carne de tasajo y otros productos del país. Los vendió bien, y retornando para este puerto su producto en azúcar y aguardiente, volvió a hacer segundo viaje con el mismo cargamento que la primera vez y para el propio destino. A imitación de éste, siguieron otros capitanes catalanes, como de

4 Estudio sobre las costumbres y descripciones interesantes de la América del Sur, por Espinosa - Noticias relativas a Montevideo, en Malaspina, Alejandro: Viaje al Río de la Plata en el siglo XVIII, reedición de los documentos relativos al viaje de las corbetas Descubierta y Atrevida e informes de sus oficiales sobre el Virrreinato, Buenos Aires, 1938, págs. 278-279.

5 Pivel Devoto, Juan E.: Raices coloniales de la Revolución Oriental de 1811, 2.^ Ed., Montevideo, 1957, pág. 108.

6 Archivo General de Indias, Buenos Aires, 141, y Barrios Pintos, Aníbal: Historia de los pueblos orientales, Montevideo, 1971, pág. 148. 
otros paises de España que, o bien hacian su viaje cargados de este puerto para aquel con carne de tasajo, sebo y harinas, por cuenta de la misma expedición, o bien fletados por uno o más individuos de este comercio y del de Buenos Aires." 7

Un ejemplo de este tipo de travesía lo encontramos en un documento referido a "gastos efectuados por el Capitán Benet Calzada, patrón del bergantín 'Ntra. Sra. de La Merced y San Feliú”", que incluye las diversas travesías efectuadas desde Barcelona. Con una tripulación básica, compuesta por el patrón y quince hombres, parte por primera vez desde la Ciudad Condal, con destino a Montevideo, el 21 de mayo de 1787; de Montevideo va a La Habana el 18 de septiembre de 1787 y de La Habana a Barcelona, luego de hacer escala en Cádiz, Málaga y Cartagena. ${ }^{8}$

\section{Incidencia de la navegación a Cuba}

El aporte de bodegas, particularmente por parte de barcos catalanes, fue fundamental para la vitalización del comercio exterior de la región. Para el Río de la Plata la cuestión de los fletes era esencial, no sólo por las distancias que lo separaban de los principales puertos de destino, sino por el tipo de mercaderías que habitualmente exportaba. Tanto los cueros, que constituían el rubro principal, como las lanas, carnes, etc., eran elementos de gran volumen que veían acrecentado sensiblemente su valor en los mercados de destino a causa del manipuleo y los fletes.

Al constituirse Cuba en un nuevo centro neurálgico de comercialización, se crearon distorsiones en el manejo del tráfico con la Península. Así por ejemplo, en noviembre de 1789 , el virrey Loreto trasmitía a Valdés la preocupación de los diputados del Comercio por haber pasado el flete de los cueros de 12 a 18 reales, "atribuyéndolo a que las embarcaciones catalanas y otras que proporcionaban la extracción se han dirigido a La Habana y otros puertos, en vista de no lograr en sus fletes el lucro que esperaban..." 9

7 Según Pivel Devoto, Juan E.: Raices coloniales..., pág. 113.

8 Archivo del Ajuntament de Barcelona, Institut Municipal d'Historia de la Ciutat. Fondo documental - B.391.

9 AGI, Buenos Aires, 383 y 106. 
MOVIMIENTO DEL PUERTO DE MONTEVIDEO ${ }^{10}$

Arribos desde La Habana Salidas hacia La Habana

$A \tilde{n} o$ N." de embarcaciones

$N .^{\circ}$ de embarcaciones

1790

1791

1792

1793

1794

1795

1796 N. de embarcaciones

TOTAL 23

4

5

8

5

8

6

14

Como puede apreciarse en el cuadro anterior, existió una importante diferencia entre el movimiento naviero que tuvo como punto de origen y destino al puerto de La Habana; situación que se vio reflejada en el tráfico general del Río de la Plata.

Si tomamos en cuenta el quinquenio 1792-1796, como contrapartida, podremos observar, en el tráfico con la Península, un porcentaje de salidas de navíos inferior al de ingresos. Esto se refleja tanto en los totales generales, como en el promedio de barcos de la línea del Mediterráneo. Mientras los arribos desde España indican para el quinquenio un promedio anual de 53,6 navíos, las salidas alcanzan a 48,6, marcando una disminución del orden del 9,32; situación que es más notable en el caso de la línea que tiene como puertos principales a Málaga y Barcelona. En este caso, el promedio anual pasa de 21 a 15,8, con una diferencia del $24 \%$. Evidentemente tal situación se vincula en gran parte con las posibilidades que abría el tráfico hacia Cuba y el señalado interés por el negocio de los fletes. La relación entre ingresos y egresos de navíos en la línea Montevideo-La Habana es significativa, ya que mientras el promedio anual de arribos en el quinquenio es de 3,2, el de partidas hacia la isla del Caribe es de 8,2 barcos. Como en el caso del bergantín "Ntra. Sra. de la Merced y San Feliú", diversos navíos procedentes de Barcelona y Málaga tomaron rumbo a Cuba. Así lo hicieron, por ejemplo, la polacra "San Francisco de Paula" y los bergantines "San Andrés

10 Ibídem, 383 y 346. 
Abelino y Ntra.Sra. del Carmen" y "Ntra. Sra. de los Angeles", llegados en 1792. 11

\section{Las exportaciones}

\section{Carnes saladas}

Como se ha señalado anteriormente, el desenvolvimiento de la producción saladeril determinó la base de las exportaciones hacia el mercado cubano, cada vez más ávido como consecuencia de la incorporación de mano de obra esclava. Si bien los primeros envíos tuvieron como destino a la Península, en la medida en que se fue asentando esta compleja industria, se procuró conservar e incrementar el vínculo con Cuba, que, rápidamente, pasó a ocupar un sólido primer lugar en las exportaciones de carnes rioplatenses. En los años previos a la guerra de 1796, que provocará tremendos inconvenientes y profundas transformaciones en el intercambio, el aumento de las cargas destinadas a aquella plaza fue constante.

En 1790, 4 embarcaciones (1 fragata, 1 paquebote y 2 bergantines), salieron de Montevideo con 14.962 quintales de carnes saladas y en el año siguiente otros 5 navíos ( 1 paquebote, 1 polacra y 3 bergantines) cargaron 11.917 quintales de igual producto.

El interés por incentivar el flujo de carnes hacia La Habana fue constante y de allí que el 16 de abril de 1793 se conseguía que el tasajo y el sebo de Buenos Aires y de otras regiones quedará exento del pago de todo derecho, incluido el de alcabala de primera venta.

\section{EXTRACCIONES POR EL PUERTO DE MONTEVIDEO SEGÚN DESTINOS 12}

Carnes saladas - quintales

\begin{tabular}{cccccc} 
Año & $\begin{array}{c}\text { puertos } \\
\text { españoles }\end{array}$ & Habana & $\begin{array}{c}\text { comercio } \\
\text { negrero }\end{array}$ & total & $\begin{array}{c}\text { \% a La } \\
\text { Habana }\end{array}$ \\
\hline 1793 & 1.088 & 27.394 & 1.860 & 30.342 & 90,28 \\
1794 & 364 & 30.145 & 4.114 & 34.623 & 87,06 \\
1795 & 2.148 & 30.576 & 4.300 & 37.024 & 82,58 \\
1796 & 2.128 & 69.090 & s/determinar & 71.218 & 97,01
\end{tabular}

1794 - Pastillas de substancia (libras): A España: 1.445 - A La Habana: 2.310

11 Archivo General de la Nación (Uruguay), Aduana de Montevideo, caja 238.

12 AGI, Buenos Aires, 346. 
Es interesante apuntar, en relación con la industrialización de carnes, que en esta época se contabilizan exportaciones de "pastillas de substancia" elaboradas en la fábrica bonaerense de los hermanos Liniers. Cada onza de estas pastillas ( 16 onzas $=1$ libra), llevaba el extracto de cinco a seis libras de carne, a lo que se sumaban pequeñas porciones de legumbres harinosas. ${ }^{13}$

\section{El sebo}

Luego de las carnes, el sebo fue el elemento más requerido en el mercado insular. Los embarques de este otro derivado de la ganadería fueron importantes. En 1790 las salidas para Cuba sumaban 9.845 arrobas de sebo en marquetas $y$ al año siguiente se embarcaban 8.316 .

Para tener una idea más acabada del peso de los envíos a La Habana, es interesante compararlos con el total exportado a España y con lo dirigido por las tres rutas que integraban el tráfico con la Península (Cádiz, Mediterráneo y Norte-cantábrico). ${ }^{14}$

$$
\text { EXPORTACIONES DE SEBO (ARROBAS) } 15
$$

DESTINOS

\begin{tabular}{lccccr} 
Año & $\begin{array}{c}\text { Total } \\
\text { España }\end{array}$ & $\begin{array}{c}\text { Vía } \\
\text { Cádiz }\end{array}$ & $\begin{array}{c}\text { Vía } \\
\text { Medit. }\end{array}$ & $\begin{array}{c}\text { Vía Norte- } \\
\text { Cantábrico }\end{array}$ & $\begin{array}{c}\text { Vía } \\
\text { Habana }\end{array}$ \\
\hline 1793 & 11.552 & 3.630 & 4.096 & 3.826 & 7.207 \\
1794 & 16.138 & 6.557 & 4.083 & 5.498 & 10.301 \\
1795 & 29.497 & 7.577 & 17.900 & 4.020 & 11.360 \\
1796 & 43.800 & 25.720 & 5.280 & 12.800 & 13.600
\end{tabular}

\section{Otros productos regionales y metálico}

Además de las carnes saladas y el sebo, cabe señalar que también salían con destino a la isla de Cuba productos tales como lanas, pieles

13 Archivo del Museo Naval (Madrid), Razón del establecimiento de las Pastillas de substancia que de orden de S.M. se ha hecho en la Provincia de Buenos Aires para uso de la Marina, Buenos Aires y Costa Patagónica, leg. 343. 1993.

14 Silva, Hernán A.: El comercio entre España y el Río de la Plata (1778-1810), Madrid,

15 AGI, Buenos Aires, 346. 
finas, badanas, aceite y pieles de lobo marino, harina, plumas y plumeros, etc., junto a una considerable cantidad de metálico. Sin embargo, a diferencia de otros destinos, las exportaciones hacia La Habana muestran una singular preponderancia de la producción regional sobre la plata embarcada hacia aquella plaza. ${ }^{16}$

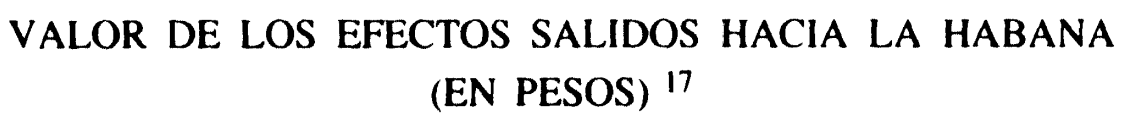

\begin{tabular}{lrrr} 
Año & Plata & Frutos & Total \\
\hline 1792 & 34.018 & 69.277 & 103.295 \\
1793 & 4.000 & 58.386 & 62.386 \\
1794 & 9.600 & 75.705 & 85.305 \\
1795 & 14.800 & 75.920 & 90.720 \\
1796 & 24.060 & 136.050 & 160.110
\end{tabular}

El proceso de incremento de las exportaciones rioplatenses durante el quinquenio 1792-1796, había sido concomitante con el aumento de los requerimientos de la plaza cubana, que en 1791 contaba con 84.590 esclavos. ${ }^{18}$

ESCLAVOS INTRODUCIDOS EN LA HABANA 19

1792

8.528

1793

3.767

1794

4.164

1795

5.832

1796

5.711

TOTAL

28.002

16 Cabe señalar que en los últimos años la cotización de la carne de tasajo se ubicó entre 11 y 12 reales el quintal y la del sebo entre 4 y $4^{1 / 2}$ pesos el quintal.

17 AGI, Buenos Aires, 346.

18 Ely, Roland T.: Cuando Reinaba Su Majestad el Azúcar, Buenos Aires, 1963, pág. 73.

19 Tornero, Pablo, Emigración... pág. 245 y Ely, Roland T., Cuando Reinaba... (señala para 1793, 3.777 ingresos en vez de 3.767), pág. 73. 
El interés por los productos rioplatenses fue muy importante. De allí que el Consulado de La Habana se ocupara del fomento de la agricultura y la elaboración de harinas, solicitando la exención de derechos de salida y de introducción a Cuba. La petición, que igualmente hacía referencia al tráfico de otros frutos regionales, recibió la atención real, por lo que, el 8 de octubre de 1796, se comunicará el otorgamiento de "libertad de derechos, no sólo en las harinas, sino también en las carnes". ${ }^{20}$ Medida importante para el tráfico interregional, que refrendaba la de 1793, pero que arribaba en momentos difíciles para el comercio.

\section{Guerra de 1796. La transformacion del comercio con Cuba}

La guerra con Gran Bretaña desatada en 1796, sacudió las bases del intercambio imperial español y provocó fuertes transformaciones en el tráfico colonial. Tanto la acción de la armada inglesa como de los corsarios, incidieron duramente sobre el comercio de Ultramar. Cercaron los puertos y efectivizaron un fuerte control en las más importantes rutas. El Río de la Plata no fue ajeno a esta crisis. La estagnación afectó tanto a los niveles de producción como de intercambio, en los que Cuba, como hemos visto, tenía una participación cada vez más creciente.

Debían buscarse vías colaterales para vivificar el comercio, por lo que el 18 de noviembre de 1797, la Corona permitió "como recurso extraordinario" que se hicieran expediciones en buques neutrales desde puertos españoles o extranjeros que mantuvieran la neutralidad. Determinación real que, combinada con dos anteriores - libertad de tráfico negrero y comercio "por via de ensayo" con colonias extranjeras- permitió que se abriera el Río de la Plata a un amplio tráfico internacional, en el que participaron activamente comerciantes y navieros de diversa nacionalidad.

En realidad, los comerciantes españoles - "especialmente de Cádiz"- pretendieron fundamentalmente revitalizar el tráfico con los puertos peninsulares y de ahí que en la real orden del 18 de noviembre se estableciera el "retorno preciso a éstos", excluyendo, al menos formalmente, otro destino alternativo. ${ }^{21}$

20 Documentos para la Historia Argentina, Tomo VII, Comercio de Indias, Consulado, Comercio de Negros y de Extranjeros (1791-1809). Buenos Aires, 1916, pág. 118.

21 Ibídem., pág. 134. 
Desde un primer momento, las interpretaciones sobre los alcances de la real orden de neutrales fueron diversas, ya que mientras desde España se procuraba obligar el tráfico de retorno, comerciantes americanos intentaron servirse de la misma con otros fines. Así surge con claridad de una comunicación efectuada el 3 de mayo de 1798 por el administrador de la Aduana de Buenos Aires a Francisco de Saavedra, indicando que "D. Tomás Antonio Romero y $\mathrm{D}$. José de María indivíduos de este comercio, fueron los que ocurrieron inmediatamente al virrey para que se les permitiese, en uso de la referida gracia, hacer sus expediciones en buques de pabellón neutral, con frutos y productos del país, a los puertos nacionales, señalando a La Habana y retornar a los que les conviniese con el producto de sus cambios". ${ }^{22}$ Evidentemente, ambos comerciantes, representantes de la nueva burguesía mercantil rioplatense, trataban de aprovechar rápidamente el nuevo sistema, promoviendo las exportaciones locales y logrando beneficios personales, en menoscabo de los intereses gaditanos que se habían presentado tradicionalmente como escollos a superar.

Pronto, desde los más diversos puertos y con variadas banderas, una importante cantidad de barcos pondrían sus proas hacia la América Hispana, y el Río de la Plata, que no era ajeno a las contingencias de la guerra, sintió la presencia de norteamericanos, hamburgueses, daneses, genoveses, prusianos, portugueses y, aún, otomanos.

La mayoría de los primeros navíos llegados con bandera neutral procedían de Cádiz y, sin demasiada preocupación por la cuestión del retorno obligado, pusieron sus proas hacia La Habana. Así lo hicieron dos fragatas, un bergantín y una polacra genovesa y dos fragatas españolas camufladas bajo el mismo pabellón neutral. ${ }^{23}$ Por otra parte, ya el 16 de noviembre del 97, dos días antes de la apertura del sistema, se había otorgado a Benito Patrón, comerciante de Cádiz, un permiso para conducir de Buenos Aires a La Habana, bajo bandera neutral, treinta mil quintales de carne salada, extrayendo de la isla azúcares y otros frutos, con tal que fueran conducidos a los puertos de la Península. ${ }^{24}$

En realidad la transformacion del tráfico hacia La Habana se registrará como consecuencia de la partida de los primeros navíos norteame-

22 AGI, Buenos Aires, 346.

23 Ibídem, 124 y 125.

24 Documentos para la Historia Argentina, Tomo VII, pág. 133. 
ricanos, antiguos navegantes de la región en búsqueda de ballenas y pinnípedos, y ya por entonces influyentes comerciantes y transportistas en el movimiento económico de Cuba. ${ }^{25}$ Consolidados la producción de carnes saladas y los vínculos económicos con Cuba, debieron generarse medidas de compromiso para paliar los efectos de la estagnación provocada por la guerra. De ahí que las autorizaciones dadas a estadounidenses para que, dejando de lado el retorno obligado a la Península, realizasen embarques directos hacia la isla caribeña, marquen el comienzo de una nueva etapa en los vínculos cubano-rioplatenses, en la que los navíos de la Unión prácticamente llegarán a monopolizar el tráfico con La Habana.

25 Silva, Hernán A.: La economía pesquera en el Virreinato del Río de la Plata, Buenos Aires, 1978. - Tornero, Pablo: "Comerciantes, hacendados y política mercantil en Cuba. La rivalidad Cadiz-Estados Unidos (1763-1800)", Actas de las IV Jornadas de Andalucía y América, Andalucia y América en el Siglo XVIII, Sevilla, 1985. 